\title{
nucture
}

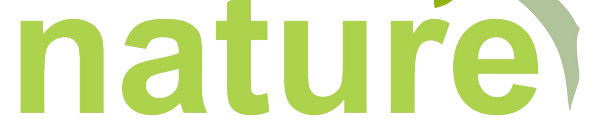

National Academic Journal of Architecture

\section{Bola Pakka: Rumah Tradisional Suku ToBalo di Kabupaten Barru}

\author{
Zulkarnain $\mathbf{A S}^{1}$ \\ Jurusan Arsitektur Fakultas Sains \& Teknologi UIN-Alauddin Makassar
}

\begin{abstract}
Abstrak- Perkembangan fungsi kegunaan bangunan khususnya bangunan tradisional itu bereneka ragam, sesuai dengan struktur masyarakat dan kebudayaan penduduk yang bersangkutan. Akan tetapi pada umumnya sebagai bangunan tradisional maupun bangunan modern mempunyai kegunaan dan fungsi yang sama. Penelitian dilakukan di Kabupaten Barru, Kecamatan Pujanannting, Desa Bulo-Bulo, Dusun Labaka. Metode yang digunakan adalah deskriptif kualitatif dengan pendekatan rasionalistik. Secara makro dapat merujuk pada penggunaan batas kawasan berupa batu, kayu maupun vegetasi sebagai bentuk pembagian teritori, orientasi pembangunan rumah mengarah pada jalan, sungai dan mata perncaharian. Bola Pakka yang merupakan rumah milik Suku To Balo secara umummemiliki kesamaan bentuk pada rumah Bugis pada umumnya, hanya saja penggunaan serta cara merakit material (proses) yang sedikit berbeda. Bola Pakka terbagi atas tiga tipe yakni Bola Sussa, Bola Sicandring dan Bola Amang.
\end{abstract}

Kata kunci: To Balo, Bola Pakka, Tradisional

Abstract - The development of utility functions of the building, especially the traditional building is various according to its societies structure and its population's culture. Generally whether in traditional buildings and modern buildings have, it has utility and similar functions. The research is conducted in Barru, District Pujanannting, village of Bulo-Bulo, Hamlet Labaka. The method of the research is descriptive qualitative with rationalistic approach. In macro, it refers to the use of area boundaries such as stone, wood and vegetation as a form of division of territory, the house development orientation which leads to the roads, rivers and ricefield Bola, only the function and the way in assembling material (process) that make them different. Pakka ball is divided into three types namely Bola Sussa, Bola Sicandaring dan Bola Amang.

Key words ; To Balo, Bola Pakka, Architecture Local 


\section{nucture \\ nature}

National Academic Journal of Architecture

\section{PENDAHULUAN}

Arsitektur tradisional adalah arsitektur yang lahir atau terbentuk oleh tradisi yang ada dengan mengangkat nilai-nilai leluhur dari daerah setempat tanpa adanya pengaruh-pengaruh dari luar. Banyak aspek yang terkait dalam pembentukan arsitektur tradisional itu sendiri baik dari segi sosial budaya, letak geografis, adat dan kebiasaan, serta ketersediaan bahan/material dari daerah setempat. Begitupun dengan Suku To Balo yang merupakan sub Suku Bugis, yang memiliki karakter khas termasuk pada wujud rumah tradisional. Abu Hamid (1978:30-31) dalam "Bingkisan Budaya Sulawesi Selatan"menuliskan bahwa rumah tradisional orang Bugis tersusun dari tiga tingkatan yang berbentuk "segi empat", dibentuk dan dibangun mengikuti model kosmos menurut pandangan hidup mereka, anggapannya bahwa alam raya (makrokosmos) initersusun dari tiga tingkatan, yaitu alam atas atau "banua atas", alam tengah "banua tengah" dan alam bawah "banua bawah". Banua atas adalah tempat dewa-dewa yang dipimpin oleh seorang dewa tertinggi yang disebut "Dewata Seuwae", yang bersemayam di "Botting-Langiq". Banua tengah adalah bumi ini dihuni pula oleh wakiIwakil dewa tertinggi yang mengatur hubungan manusia dengan dewa tertinggi serta menggawasi jalannya tata tertib kosmos. Banua bawah disebut "Uriliyu” (tempat yang paling dalam) dianggap berada di bawah air. Semua pranata-pranata yang berkaitan dengan pembuatan atau pembangunan rumah harus berdasarkan kosmologis yang diungkap dalam bentuk makna simbolis-filosofis, yang diketahuinya secara turuntemurun dari generasi kegenerasi.

Menurut Mangunwijaya (1992:95-96), bahwa bagi orang-orang dahulu, tata wilayah dan tata bangunan alias arsitektur tidak diarahkan pertama kali demi penikmatan rasa estetika bangunan, tetapi terutama demi kelangsungan hidup secara kosmis. Artinya selaku bagian integral dari seluruh "kosmos" atau "semesta raya"yang keramat dan gaib. Sehingga dengan keunikan yang ditawarkan oleh arsitektur tradisional ini maka peneliti tertarik untuk mengulas lebih dalam tentang Perkembangan Wujud RumahTradisional Suku ToBalo (Bentong) yang ada di Kab.Barru Desa Bulo-Bulo. Tujuan penelitian ini adalah mendeskripsikan dan mengidentifikasi perkembangan wujud arsitektural Suku To Balo (Bentong)

\section{METODE PENELITIAN}

N Metode penelitian digunakan deskriptif kualitatif dengan pendekatan rasionalistik. ๙Deskriptif berusahamenggambarkan dan menginterpretasi objek sesuai dengan apa Eadanya (Best 1982).Kualitatif sebagai prosedur penelitian yang menghasilkan data T deskriptif berupa kata-kata tertulis maupun lisan dariorang-orang dan pelaku yang diamati untuk diarahkan pada latar dan individusecara holistic (Moleong 2002). Rasionalistikmerupakan metode dimana peneliti bertindaksebagai instrumen utama, peneliti melakukaninterview secara mendalam dan mendetailsecara silang dan berulang untuk dapatmengetahui perkembangan sosial budaya, danbangunan 


\section{nucture

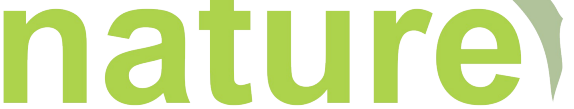

National Academic Journal of Architecture

tradisional sebagai produk dari budaya serta perubahan-perubahan yang mungkin terjadi (Moehadjir 1996).

\section{Metode Pengumpulan Data}

1. Pengumpulan Referensi; Referensi yang dimaksud ialah data-data sementara yang bersifatmembimbing/mengarahkan pola penelitian yang diinginkan, dapat pula sebagaipetunjuk penelitian. Pengumpulan referensi ini dilakukan sebelum ke lokasipenelitian, dan setelah melakukan survey langsung, guna melengkapi data yangsifatnya teoritis.

2. Wawancara; Untuk mengawali pengambilan data, maka dilakukan wawancara (interview)terhadap pemilik rumah sebagai objek penelitian serta masyarakat setempatsebagai sumber pendukung. Ini bermaksud menambah nilai valid data penelitian.

3. Pengamatan Langsung di Lokasi PenelitianPengamatan ini berupa peneliti berperan aktif secara langsung danmenyeluruh mengumpulkan data secara lengkap berisi seluruh informasi yang dibutuhkan.

\section{PEMBAHASAN}

Lokasi penelitian berada di Sulawesi Selatan tepatnya di Kabupaten Barru, Kecamatan Pujanannting, Desa Bulo-Bulo, Dusun Labaka.

\section{A. Arsitektur Lingkup Makro}

Secara umum pola tata massa rumah Suku To Balo merupakan pola menyebar yaitu Pola pemukiman yang mengikuti jalan dan lokasi mata pencarian. Selain kedua aspek tersebut keamanan juga merupakan salah satu pertimbangan yang penting untuk menentukan lokasi membangun rumah, misalkan daerah yang datar atau daerah yang tidak mudah longsor.

Lokasi penelitian merupakan daerah berkontur karena lokasi berada pada area pegunungan. Sehingga mengharuskan masyarakat dalam membagi batas wilayahnya menggunakan bahan dan material yang ada (konvensional). Ini didasari karena keterjangkauan dan ketersediaan alat dan material.Penggunaan material sebagai batas teritori dominan menggunakan batualam, kayu serta deretan vegetasi.

Secara umum pertimbangan dalam orientasi lingkungan pada suku to Balo ada 3 aspek pertimbangan yaitu :

1. Berorientasi pada jalan yaitu semenjak pemerintah membuat jalan maka sebagian besar rumah di Suku To Balo menghadap ke jalan untuk memudahkan dalam akases pencapaian.

2. Mengikuti daerah mata pencarian yaitu masyarakat desa Bulo-Bulo dalam hal ini Masyarakat suku To balo berpropesi sebagai petani baik itu petani yang bekerja di sawah maupun yang bekerja di ladang atau kebun selalu berusaha membuat hunian atau tempat tinggal di sekitar tempat mata pencarian mereka karena pertimbangan efisiensi.

3. Apabila di sekitar pemukiman ada sungai maka hunian tidak boleh menghadap ke sungai karena menurut kepercayaan masyarakat suku to balo jika rumah menghadap ke arah sungai "maccamming I yaro bolae" yang makna atau dampaknya akan berpengaruh pada psifat dan sikap penghuni rumah yang kurang baik. 


\section{B. Arsitektur Lingkup Mikro}

\section{nucture \\ nature}

National Academic Journal of Architecture

Bentuk rumah pakka pada dasarnya sama dengan bentuk rumah bugis lainnya yaitu bentuk panggung, rumah pakka pada dasarnya tidak hanya difungsikan sebagai tempat tinggal atau berteduh. Rumah juga bisa di simbolkan sebagai tingkat strata social bagi pemiliknya, pada bola pakka tingkatan strata sosial tidak terlalu di tonjolkan hal itu dapat terlihat pada bentuk bangunan yang sederhana dari bahan maupun strukturnya, bola pakka berbentuk panggung yang terbagi atas bagian bawah, bagian tengah dan bagian atas, ketiga pembagian ini memiliki fungsi yang berbeda-beda.

\section{Lokasi Perancangan}

Konsep utama desain tapak yaitu kenyamanan aktivitas sirkulasi manusia dan kendaraan, dan kesesuaian zoning elemen-elemen tapak, perencana ingin agar aktivitas sirkulasi dalam tapak berjalan lancar, dan penempatan elemen tapak sesuai dengan sifat zoningnya, misalnya penempatan pintu masuk tapak yang sifatnya publik maka perlu diletakkan di area depan yang berhubungan langsung dengan jalan utama sedangkan bangunan utama yang sifatnya privat maka diletakkan di area yang lebih khusus.

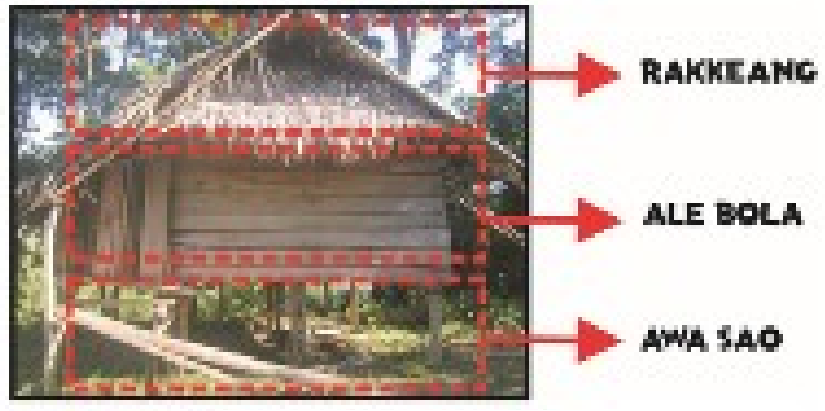

Gambar 1: Analogi Kosmologi Ruang

Filosofi bentuk dari bangunan rumah tradisional Suku To Balo diambil dari bentuk dasar rumah tradisional Suku Bugis pada umumnya yaitu "Sulapa'Appa", yakni perbentuk persegi.

Proses pembangunan pada rumah masyarakat To Balo menggunakan sistem gotong royong yang meliputi saudara, keluarga dan tetangga. Sistem gotong royong ini tidak hanya digunakan pada acara mendirikan rumah tetapi juga pada acara pengadaan bahan dan material rumah serta pada saat panen hasil pertanian/perkebunan. Proses pembangunan rumah ToBalo terdiri dari beberapa tahap:

a. Proses Pengadaan Bahan Bangunan; Sebelum memulai proses pembangunan BolaPakka, pemilik terlebihdahulu menyiapkan semua bahan bangunan yang akan digunakan untuk membangun rumah dengan dasar pertimbangan semua bahan atau material harus lengkap dan sebisa mungkin untuk jumlah bahan dilebihkan dengan tujuan untuk antisipasi kerusakan pada bahan dan kekurangan jumlah.

b. Pemilihan Waktu; Sebelum memulai proses pembangunan rumah,pemilik rumah terlebih dahulu meminta pertimbangan atau petunjuk kepada sanro bola untuk menentukan hari memulai membangun rumah, setelah harinya ditentukan selanjutnya adalah membangun rumah yang ketentuannya dimulai pada pagi hari. 


\section{nucture

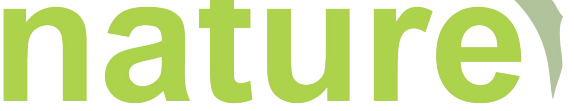

National Academic Journal of Architecture

c. Penentuan possi bola; Pemilihan tiang utama dalam bola pakka dipilih material kayu yang terbaik biasanya dipilih oleh sanro bola dan perletakan tengah rumah.

d. Pengerjaan Bola Pakka; Diawali degan mendirikan Alliri Pakka pada area yang telah ditentukan, kemudian lanjut dengan pemasangan Padongkodengan pemasangan Arateng (balok anak), kemudian dilanjutkan degan pemasangan Pattikkang dibagian ujung atas alliri, pada proses selanjutnya dimulai pembuatan rangka ate' dan pemasangan materialnya seperti alangalang atau ijuk. Setelah pembuatan atap selesai dilanjutkan dengan penyususnan lantai dengan cara diikat pada BalokArateng. Pada proses finishing dilakukan penyusunan dinding dengan cara di ikat ke alliri.

e. Syukuran; Setelah proses mendirikan rumah selesai dan sebelum memasuki rumah masyarakat ToBalo memiliki Adat MapenreBoladimana pada proses adat ini pemilik rumah menyediakan makanan atau Beppa yang manis-manis seperti Baje, Onde-Onde, Lana-Lana,Apang, Burongko dan lain-lain, tergantung dari kemampuan dan keihklasan pemilik rumah. Dengan harapan "Cenning'IAtinnaPunnaBolae", serta bermaksud agar pemilik rumah memiliki kehidupan yang harmonis dari filosofi rasa manis.

Orentasi bangunan pada rumah tradisional vernakular pada Suku ToBalopada umumnya terbagi menjadi 2 arah orentasi, yaitu : menghadap ke jalan utama, hal ini dikarenakan masuknya aturan pemerintah yang mengarahkan seluruh rumah di daerah To Balo harus menghadap ke jalan. Kedua rumah To Balo menghadap ke arah perkebunan atau pertanian, orentasi ini berkaitan dengan efektifitas pencapaian ke area pertanian, selain itu orentasi ini bermaksud untuk memudahkan menjaga area perkebunan dari gangguan hama seperti babi. Selain itu masyarakat To Balo juga di kenal dengan Suku Bentong, Suku Bentong menggunakan tiga jenis bahasa yaitu ammatoa, bugis, dan makassar. Orentasi rumah yang menghadap ke arah pertanian atau perkebunan ini memiliki kemiripan dengan orentasi rumah Ammatoa (rumah adat kajang) yang menghadap ke arah hutan atau yang biasa kita kenal sebagai sumber kehidupan bagi masyarakat ammatoa.

\section{Tata Ruang}

Ruang padaBola Pakkasecara spacial horizontal terdiri dari; Teras (Degodego)befungsi sebagai tempat menerima tamu sebelum dipersilahkan masuk ke dalam rumah, Ruang bagian luar (Lontang ri saliweng)digunakan sebagai tempat menerima tamu yang memiliki kepentingan lebih penting dan digunakan sebagai kamar tidur kepala keluarga, Ruang bagian tengah (Lontang tengga) sebagai tempat keluarga berkumpul dan bercengkrama satu sama lain dan sekaligus digunakan untuk kamar gadis, Ruang bagian dalam (Lontang ri laleng) sebagai dapur dan passilo, Ruang Tambahan (Passilo) tempat meletakkan barang seperti lemari dan peralatan-peralatan memasak. Sedangkan pemabagian ruang secara spacial vertikal teridiri dari; Ruang atas (Rakkeang)digunakan sebagai tempat penyimpanan hasil panen dan barang-barang berharga, Ale bola (badan rumah) Sebagai tempat beraktifitas yang utama seperti makan, tidur dll, dan Bagian bawah rumah (Awa bola) digunakan sebagai tempat penyimpanan ternak dan 


\section{nucture}

\section{nature}

National Academic Journal of Architecture bale-bale. Selain itu juga dapat digunakan sebagai tempat beraktifitas jika ada acara-acara penting yang dilakukan oleh penghuni rumah.

Bolapakka memiliki tiga tipe berdasarkan pembagian ruang berdasarkan ruanganya, yang biasa disebut lontang, yakni:

a.

b. Satu lontang (bola sussa)"iyasseng bola sussa apa bara ma biccu mi bolana na untuk 2 mi tau na ala de na coco ma'terima tamu pa'na de nalai bolana", yang artinya dinamakan bola sussa karna ukuran rumah yang kecil dan hanya diisi oleh 2 orang dan tidak cocok untuk menerima tamu karna rumah yang tidak cukup untuk menampung banyak orang.
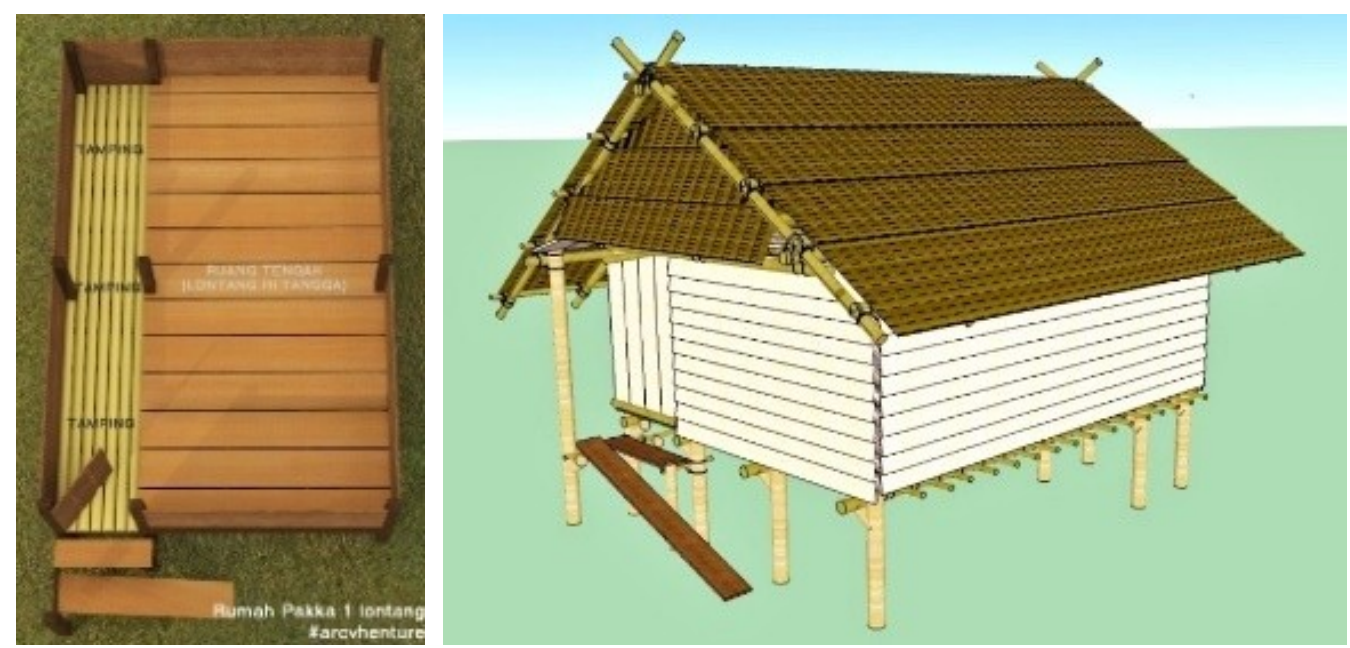

Gambar 2. Bola Sussa
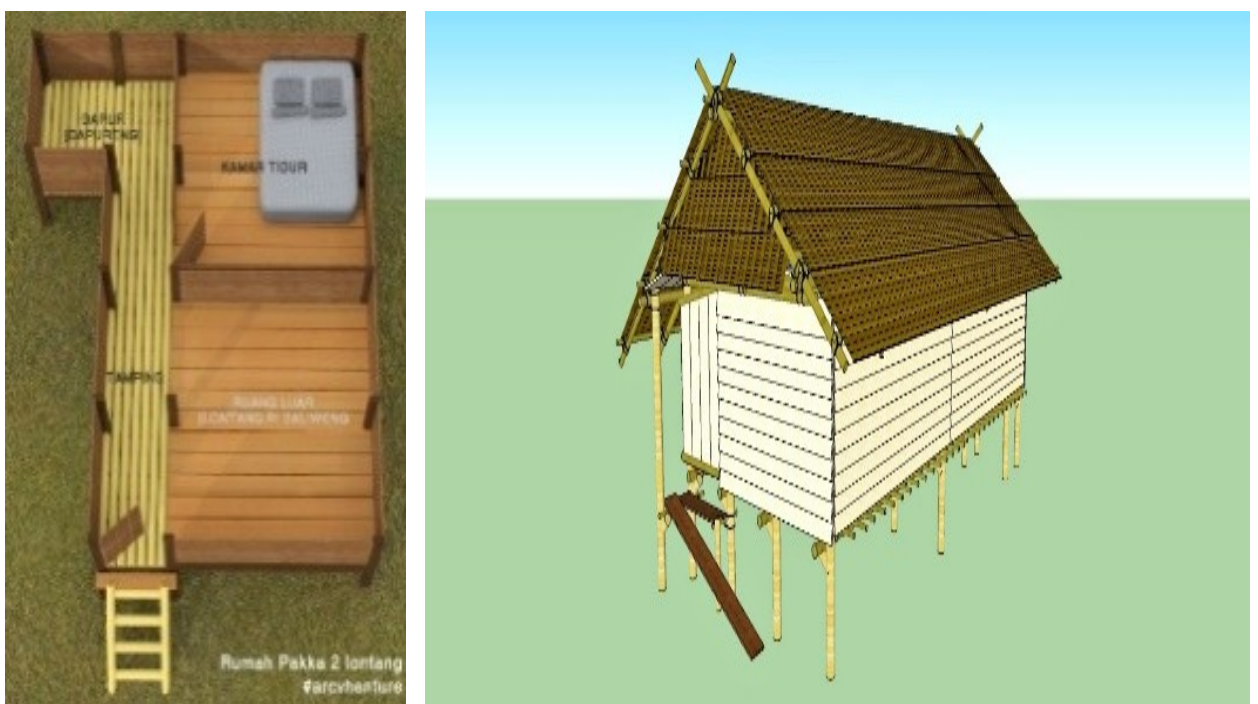

Gambar 3. Bola Sussa 


\section{nucture naturel}

National Academic Journal of Architecture

c. Dua lontang (bola sicandring) "bola sicandring saba punna bolae maccarita toni ri laleng, maccarita toni ri saliweng" artinya rumah pacaran karena penghuni rumah dapat bercerita di ruang dalam dan luar.
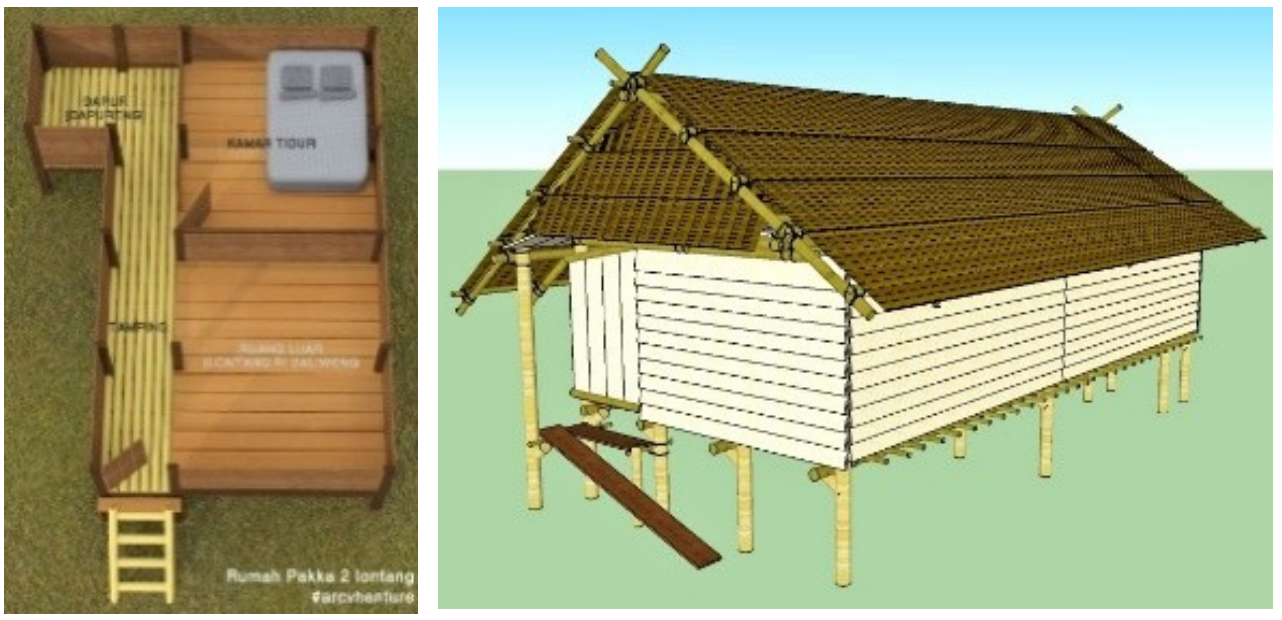

Gambar 4. Bola Sicandring

d. Tiga lontang (bola amang) dinamakan bola amang karena rumah ini dianggap sudah aman dan memenuhi fungsi rumah yang sesungguhnya seperti menerima tamu, membuat acara besar, pembagian ruang dan fungsi ruang yang jelas antara penghuni rumah dan tamu.

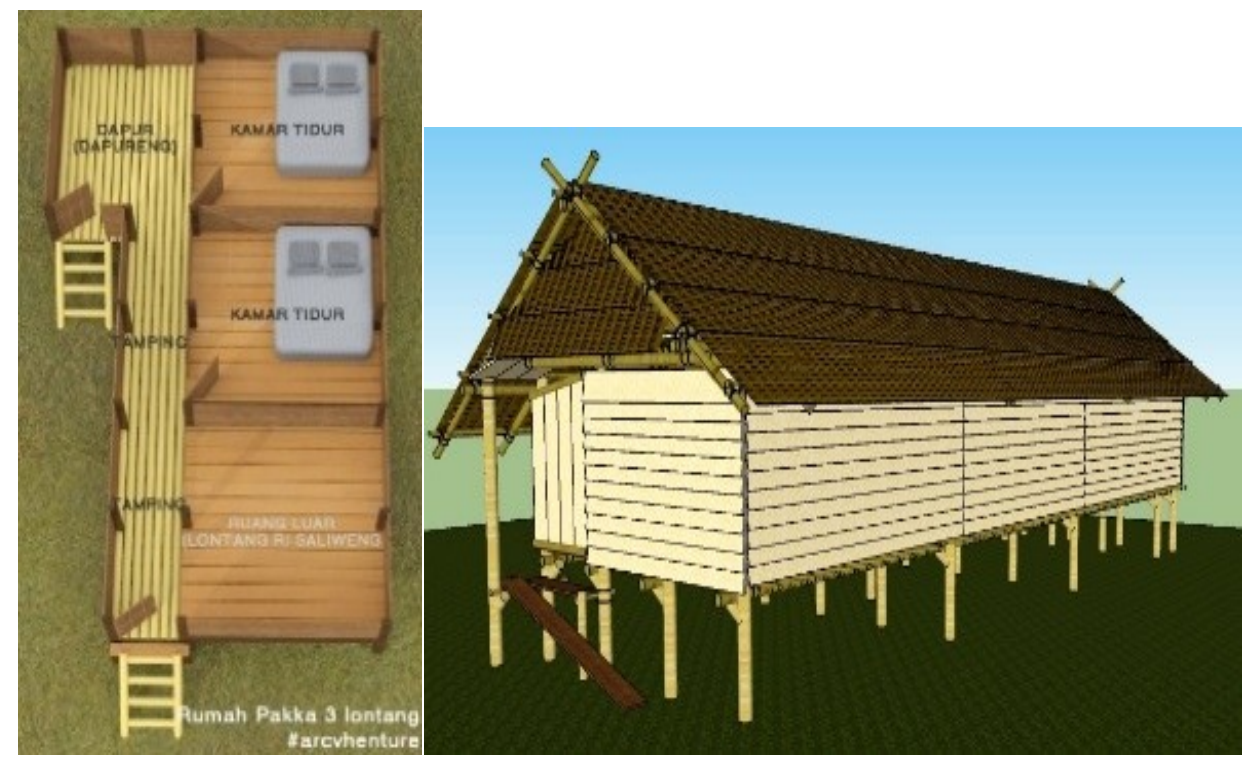




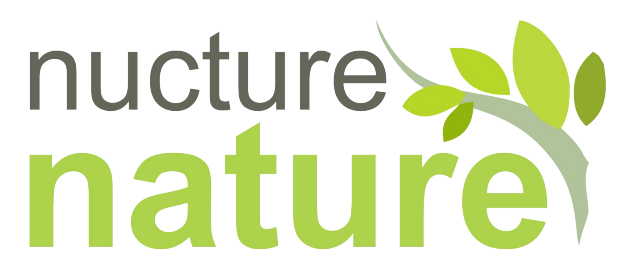

National Academic Journal of Architecture

Gambar 5 . Bola Amang

Bola pakka dalam penataan ruang luar memiliki beberapa unsur pembentuk yakni tempat ternak, industri rumahan (pembuatan gula aren), tempat menjemur hasil pertanian, serta batas lingkungan hunian. Keempat unsur ini adalah objek pendukung dari keberadaan Bola Pakka yang menunjang aktifitas di luar rumah.

\section{Bentuk dan Sistem Struktur}

Bolapakka pada dasarnya sama dengan rumah biasanya yang memiliki aspek pendekatan desain, baik arsitekrtur maupun non-arsitekrtur yang biasa kita kenal dengan filosofi bentuk bangunan. Meskipun bolapakka sangatlah sederhana bangunan ini sangat memperhatikan keadaan lingkungan, sehingga bisa berdiri dalam keadaan iklim apapun. Dalam masyarakat to Balo/Bentong tingkat strata sosial pada bentuk rumahnya sangatlah sulit untuk menentukannya, karena jika kita melihat dan mengaitkan dari gaya arsitektur pada rumah Bugis lainnya ciri-ciri tersebut jarang dan hampir tidak ditemukan pada bolapakka, maksudnya bentuk yang bisa mencitrakan bola yang memiliki tingkat strata sosial yang tinggi tidak bisa kita nilai dari bentuk timpalaja, tangga maupun jumlah ventilasi. Namun untuk membedakan tingkat strata sosial pada bola pakka kita hanya dapat melihat jumlah lontang yang ada pada bolapakka, simbol inilah yang menjadi pembeda tingkat strata sosial kepemilikan rumah baik yang bangsawan maupun masyarakat biasa.

Proses pendirian bolapakka juga memiliki proses yang sangat selektif karena bagi masyarakat pemilihan struktur sangatlah penting karena penggunaannya berlangsung lama. Masyarakat dalam mendirikan bolapakka menggunakan sistem knock down. Dalam mendirikan BolaPakka tidaklah muda karena pengambilan material struktur harus menggunakan material yang baik, bukan hanya itu untuk mengambil bahan bangunan juga memiliki cara tersendiri misalnya pada pemilihan alliri pakka, batang pohon yang dipilih harus tua dan dapat bertahan serta mudah untuk dibentuk pada saat pekerjaan, karena alliripakkamenggunakan sistem penancapan tiang, selain itu alliripakkaini pada saat ditebang harus satu siku dari tanah dan juga harus memiliki pakka. Bentuk pakkaini bertujuan sebagai penangkap balok yang akan dibentangkan dan menopang balok lantai pada bolapakka.

Teknik pengukuran menggunkan antropometri tubuh seperti jari, pengukuran dengan menggunakan jari pada bolapakka menghindari letak urat syaraf yang bisa membahayakan diri pada saat mengukur atau mendirikan rumah karena seperti kita ketahui urat syaraf adalah jaringan tubuh yang sangat sensitive dan dapat menyebabkan luka yang cukup parah. Selain itu pengukuran tinggi ruang pada bagian badan rumah menggunakan antropometri dari tinggi tubuh kepala keluarga, cara pengukuran ini dimaksudkan bahwa kepala keluarga yang akan menjadi orang yang bertanggung jawab di dalam kehidupan rumah tangga.

Struktur bawah pada BolaPakka yaitu alliri pakka yang menancap kedalam tanah yang bertujuan agar dapat menahan beban, selain itu alliri pakka memiliki ciri yang sesuai namanya yaitu pakka atau bercabang dan berbentuk bulat degan ukuran yang disesuiakan.Struktur tengah terdiri dari Padongko berfungsi sebagai balo induk yang berfungsi sebagai pembagi ruang yang terletak di atas alliri pakka yang melintang secara horizontal dan meghubungkan antara alliri 


\section{nucture}

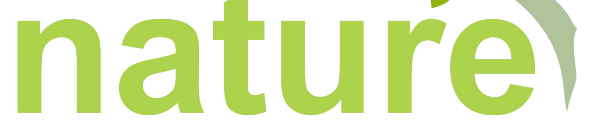

National Academic Journal of Architecture

pakka; Arrateng berfungsi sebagai dudukan papan lantai, arrateng terletak di atas padongko. Arateng pada Bola Pakka adalah kayu yang berbentuk bulat yang disusun diatas padongko yang ukurannya diproporsikan dan disesuikan; Papan Lantai (salima) berrfungsi sebagai pijakan untuk aktifitas di dalam ruang. Papan lantai berbentuk lembaran yang disusun dengan rapi yang letaknya berada diatas arateng; Dinding (rendiring) berfungsi sebagai penutup bangunan bagian depan, belakang, samping kira dan kanan. Terdiri dari susunan papan secara horizontal dan ikat atau dijepit.

\section{Gambar 6. PolaStruktur Bola Pakka}

Struktur ataspada bolapakkaterdiri dari: Pasollaberfungsi sebagai rangka penutup bangunan pada bagian ate' pasolla terbuat dari aju bitti; Tinra befungsi sebagai alliri pa'jaga pada balok pasolla sehingga tidak terjadi fraktur pada ate'.

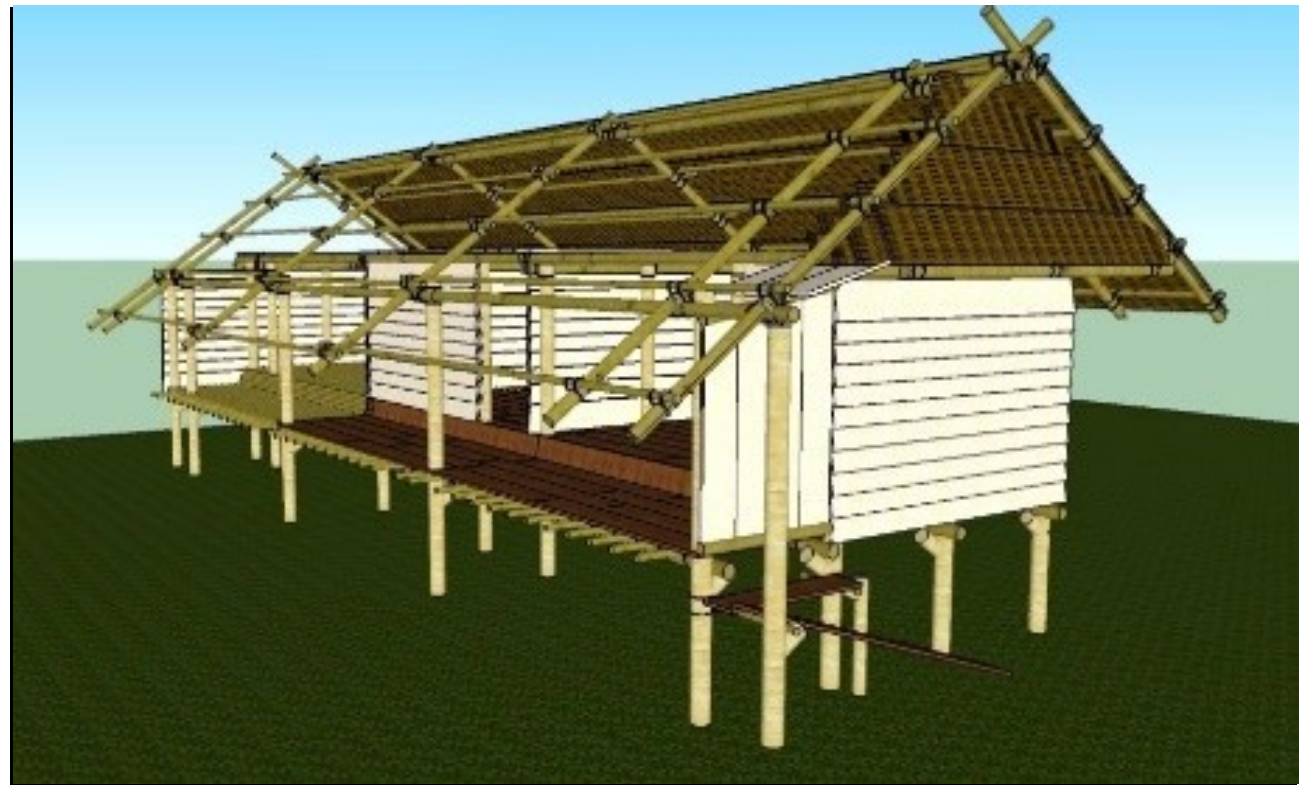

Pa'bakallang berfungsi sebagai rangka tempat perletakan atap ijuk letak pa'bakallang memilki jarak bentang berkisaran $30 \mathrm{~cm}$, letak ini bertujuan untuk menjaga agar atap ijuk tidak merembes kedalam bangunan akibat beban air. Untuk bahan pada pa'bakalllang terbuat dari kayu bitti; Coppo'na berfungsi sebagai balok tempat pengikat ate' ijuk pada bagian ujung atap yang tujuannya untuk mencega rembesan air. Bahan untuk struktur ini terbuat dari kayu bitti; Timba Laja sebagai penutup atap juga sebagai area sirkulasi udara.

\section{KESIMPULAN}

Rumah Pakka merupakan rumah milik Suku To Balo yang memiliki kesamaan bentuk pada rumah Suku Bugis pada umumnya. Hanya saja penggunaan serta cara merakit material (proses) yang sedikit berbeda, mereka lebih merujuk ke sistem konvensional atau manual. Sebelum proses pembangunan rumah, semua bahan bangunan sudah harus siap termasuk menentukan hari baik mendirikan bangunan dan menetukan letak posi bola. Bola Pakka terbagi atas tiga tipe yang 


\section{nucture nature}

National Academic Journal of Architecture memiliki fungsi yang berbeda yakni Bola Sussa(1 lontang), Bola Sicandring (2 lontang), dan Bola Amang (3 lontang).

ฮิ Gartiwa, Marcus. (2011). Morfologi Bangunan dalam Konteks Budaya. Bandung: Penerbit Muara Indah Bandung. స Hamid, abu. (2007). Sejarah Bone. Makassar: Dinas Kebudayaan Dan Pariwisata Kabupaten Bone.

$\frac{\sigma}{\sigma}$ Izarwisman, dkk. (1985). Arsitektur Tradisional Sulawesi Selatan. Inventarisasi dan Dokumentasi Kebudayaan Daerah Sulawesi Selatan, Departemen Pendidikan dan Kebudayaan. Koentjaraningrat. (1977). Metode-metode Penelitian Masyarakat. Jakarta:Gramedia. Lexy J. Moleong. (2002). Metodologi Penelitian Kualitatif. Bandung: PT.Remaja Rosdakarya.

Mattulada, A. (1998). SejarahMasyarakat dan Kebudayaan Sulawesi selatan. Ujung pandang: Hasanuddin University Press.

Noeng, Muhadjir. (1996). Penelitian Kualitatif edisi ke 3. Yogjakarta: PT Bayu Indra Grafika. 


\section{nucture naturel}

National Academic Journal of Architecture

Rapoport, Amos. (1969). House Form and Culture. Prentice Hall, Englewood Cliffs NJ.

Rudofsky, Bernard. (1964). Architecture without Architects. New York: Museum of Modern Art. Sekolah Menengah Atas Negeri 1 Surade. (2012). Makalah Suku To Balo (Orang Belang).

Alamat Website: http://beenet215.wordpress.com/makalah-suku-tobalo. Diakses pada juni 11 th 2015. 